\title{
DOES SOCIALITY DRIVE THE EVOLUTION OF COMMUNICATIVE COMPLEXITY? A COMPARATIVE TEST WITH GROUND-DWELLING SCIURID ALARM CALLS
}

\author{
Daniel T. Blumstein* and Kenneth B. Armitage \\ Department of Systematics and Ecology, University of Kansas, Lawrence, Kansas 66045
}

Submitted September 18, 1996; Revised February 24, 1997; Accepted March 4, 1997

\begin{abstract}
While sociality has been hypothesized to drive the evolution of communicative complexity, the relationship remains to be formally tested. We derive a continuous measure of social complexity from demographic data and use this variable to explain variation in alarm repertoire size in ground-dwelling sciurid rodents (marmots, Marmota spp.; prairie dogs, Cynomys spp.; and ground squirrels, Spermophilus spp.). About $40 \%$ of the variation in alarm call repertoire size was explained by social complexity in the raw data set. To determine the degree to which this relationship may have been influenced by historical relationships between species, we used five different phylogenetic hypotheses to calculate phylogenetically independent contrasts. Less variation was significantly explained in contrast-based analyses, but a general positive relationship remained. Social complexity explained more variation in alarm call repertoire size in marmots, while sociality explained no variation in repertoire size in prairie dogs and no variation in phylogenetically based analyses of squirrels. In most cases, substantial variation remained unexplained by social complexity. We acknowledge that factors other than social complexity, per se, may contribute to the evolution of alarm call repertoire size in sciurid rodents, and we discuss alternative hypotheses. Our measure of social complexity could be used by other researchers to test explicit evolutionary hypotheses that involve social complexity.
\end{abstract}

While it is often implied that sociality drives the evolution of communicative complexity (e.g., Marler 1977; Waser 1982; Marler and Mitani 1988; Philips and Austad 1990; Hauser 1996), the hypothetical relationship is rarely explicitly stated, and the relationship has never been formally tested. Marler (1977, p. 46) predicted that "the richest elaboration of systems of social communication should be expected in intraspecific relationships, especially where trends towards increasing interindividual cooperation converge with the emergence of social groupings consisting of close kin." Waser (1982, p. 118) also linked sociality to communicative complexity when he noted "the value to a signaler of broadcasting information to recipients, and thus the degree to which selection favors specialized 'information-transfer' abilities, depend[s] on the social system." Testing the relationship between social complexity and communicative complexity requires explicit definitions of both variables in terms of complexity and comparative tests. In this article, we focus on the evolution of alarm call repertoire size in ground-dwelling sciurid rodents (marmots, Marmota spp.; prai-

* To whom correspondence should be addressed; E-mail: marmota@falcon.cc.ukans.edu.

Am. Nat. 1997. Vol. 150, pp. 179-200.

(c) 1997 by The University of Chicago. 0003-0147/97/5002-0002\$03.00. All rights reserved. 
rie dogs, Cynomys spp.; and ground squirrels, Spermophilus spp.). We derive a continuous and objective measure of social complexity from demographic data and use this variable to explain variation in alarm call repertoire size.

Ground-dwelling squirrels are an ideal taxon to ask questions about the evolutionary impacts of social variation on communicative complexity. There is a large body of literature on social variety in marmots, prairie dogs, and ground squirrels (e.g., Murie and Michener 1984; Barash 1989; Hoogland 1995; Bibikow 1996). Social organizations range from those species that disperse immediately following weaning and live more or less solitary lives to those that exhibit delayed dispersal, in which overlapping generations of individuals share a home range and interact amicably. All ground-dwelling sciurids emit alarm calls, and repertoire size varies. Moreover, alarm calls are relatively common vocalizations and generally quite loud; estimates of repertoire size should be reasonably accurate. Thus, there is sufficient variation in both social organization and alarm call repertoire size for potential adaptive coevolution.

\section{COMPLEXITY DEFINED}

The term complexity is often used but rarely explicitly defined (McShea 1991). Others (e.g., Cole 1985) estimated behavioral complexity by counting the number of discrete behaviors. Simply put, the logic is that more discrete behaviors can be used more ways (Bonner 1988). While this definition may be a reasonable first approximation to estimating complexity, a richer definition of complexity implies more than simply counting the numbers of discrete behaviors. Complexity also implies some degree of variation or unpredictability in how elements (such as behaviors) are arranged (McShea 1991). Dawkins (1992, p. 265) presents a nice analogy to illustrate complexity. To compare the complexity of a lobster and an earthworm, write a book to describe each species. The longer book describes the more complex organism. All explicit definitions of complexity acknowledge that it must be viewed in a continuous fashion (e.g., Shannon and Weaver 1949; Sanders and Ho 1981; Cole 1985; Bonner 1988; McShea 1991). Thus, we must define sociality in a continuous way that reflects complexity.

\section{Social Complexity}

The evolution of sociality or social behavior is often studied by treating social variation categorically (e.g., Winston and Michener 1977; Prum 1994; Crespi 1996), and social systems are often classified in ways unrelated to complexity (e.g., Crook and Gartlan 1966; Wittenberger 1979; Armitage 1981; Croft 1989). Previous classifications that specifically acknowledged variation in complexity specified only a few somewhat subjective levels of complexity (e.g., Eisenberg et al. 1972). Colleagues have noted that perhaps complexity has little explanatory utility when thinking about social evolution because what ultimately matters is the relative fitness of different social structures, not complexity. We believe this is logical advice. But different social structures may result from differences in complexity, and/or complexity may be associated with different 
social structures. Thus, complexity and social structure may be inseparable. If so, complexity is an objective measure of differences in social structure. Finally, and correctly or incorrectly, the evolution of complexity is a central theme in contemporary biology (Bonner 1988; McShea 1991, 1996; Szathmáry and Maynard Smith 1995). Thus, to study the relationship between social complexity and communicative complexity, we must explicitly define sociality in terms of complexity.

Group size is sometimes used as a measure of sociality (e.g., Eisenberg 1981; Janson and Goldsmith 1995). Yet social group size is an inadequate metric of social complexity because social behavior involves relationships between individuals, and the diversity of these relationships is not captured by simply using group size. Social behavior has been classified by the nature of the relationship (Alexander 1974), by the stability or persistence of the relationship (Foley and Lee 1989), by a species mating or grouping system (Wittenberger 1979; Wrangham 1986), by a series of ecological factors (Crook and Gartlan 1966), and by a series of life-history, ecological, and/or social variables (Clutton-Brock and Harvey 1977; Armitage 1981; Di Fiore and Rendall 1994). Because social behavior is typically defined categorically, it is not immediately obvious how to compare different social systems objectively with respect to variation in complexity. A new metric of social variation is required to specifically quantify complexity. This metric would ideally be broadly applicable to diverse taxa.

Previous classifications of primate, macropod, and ground-dwelling sciurid sociality subjectively classified species into social grades (e.g., Eisenberg et al. 1972; Armitage 1981; Michener 1983; Croft 1989). For sciurids, classification depended, in part, on the methods used and on available data. Michener (1983) classified species according to kinship and spatial distributions of different age and sex animals; for many species, detailed information on kinship and social structure was unavailable. The five social grades proposed in other works (Armitage 1981; Michener 1983) were not always congruent, and there was no obvious way to describe the continuous nature of sociality (i.e., variation within a social grade was ignored).

Classical information theory (Shannon and Weaver 1949) provides the tools to quantify complexity continuously and objectively. The number of binary digits (bits) required to describe a social system objectively defines social variation along a metric of complexity (also see Sanders and Ho 1981). In the communication literature, the Shannon-Wiener formula,

$$
H(X)=-\sum p(i) \log _{2} p(i),
$$

defines the amount of potential information in a message, $H(X)$, given the relative frequency, $p(i)$, of a number of different signals, $X_{i}$. The variable $H(X)$ is the number of bits of information required to describe a communicative system with $i$ different signals each occurring with a probability $p$. The simplest case is where there is a single signal given with $100 \%$ probability: $p(i)=1 ; \log _{2}$ $p(i)=0$. In this case, $H(X)=0$, for no information is required to describe something that happened all the time. Analogously, if individuals always lived 
alone, the species' social system would be very simple and would require few bits to be described fully.

To use information theory to describe social variation, we assumed that species with more demographic roles were more complex than those with fewer roles. A role is a "socially expected behavior pattern usually determined by an individual's status in a particular society" (Webster's New Collegiate Dictionary, 19th ed., s.v. "role"). For instance, two roles in a social group may be breeding and nonbreeding. Many types of roles change over time: nonbreeders may mature into breeders; breeders may not breed every year; subordinates may become dominants; a territory holder may become a floater; and so forth. Roles may also vary in their degree of specification: breeders and nonbreeders may be classified according to sex. Thus, a group may have both female breeders and female nonbreeders. Social structure can be described based on the roles present in a social group. Thus, some groups may have a single breeding male, no nonbreeding males, and a mix of breeding and nonbreeding females. Our use of the term role is very similar to Hinde's (1975) discussion of relationships. Sociality can be described by noting the nature and variety of relationships or, using our terminology, roles.

While it would be ideal to acknowledge the diversity and flexibility of roles present in social groups, such data are typically unavailable for many species, and more specific roles must emerge from demographic roles. We defined roles based on age and sex as reported in the literature, and we used social groups as the unit of analysis. For instance, some marmots had social groups containing adults, 2-yr-old and yearling nonbreeding individuals, and juveniles born that year. Some Spermophilus social groups had a single female with her young of the year. In all cases in which adult males and females lived together, we defined a role for adult males and a role for adult females. Our classification may oversimplify behavioral complexity. We do not intend our descriptions of complexity to be final; rather, we view them as the best possible given available information. The methodology permits us to quantify social complexity objectively and is amenable to the addition of new data.

We summarized the literature on the demographic structure of social groups and calculated an $H(X)$ for each role $(H(X)$ adult males, $H(X)$ adult females, etc.). Specifically, for each role, we counted the number of social group years (a social group studied for a year) that contained a particular number of individuals (e.g., $0,1,2,3, \ldots, n$ adult males, etc.) and used these counts to calculate each $H(X)$. The sum of all the $H(X)$ 's for a given species, $H(X)_{\mathrm{t}}$, was the total number of bits required to describe the social structure of that species. However, $H(X)_{\mathrm{t}}$ alone does not acknowledge kin structure. Envision two social systems with exactly the same $H(X)_{\mathrm{t}}$ but differing in kinship. Because kinship adds new dimensions to social relationships, we would like those social groups with kinship to be more complex than those without kinship. One possible way to do this that is amenable to comparative study would be to incorporate the time to natal dispersal. There is variation in the time to natal dispersal among grounddwelling sciurids that generates kin structure in social groups. To incorporate the added complexity of kin structure created by delayed dispersal, we multiplied 
each $H(X)_{\mathrm{t}}$ by a number reflecting the time to natal dispersal, $T_{\text {nd }}$. Species that dispersed before their first hibernation or during their first active season were multiplied by 1 , species that dispersed before their second hibernation or during their second active season were multiplied by 2 , and species that dispersed after their second hibernation or active season were multiplied by 3 . In doing so, we are aware that sciurids with more demographic roles also have delayed dispersal. Other taxa may increase social complexity solely by immigration and not by delayed dispersal. While we intend this metric to be generalizable to other taxa, we are aware that we further increase the social complexity for complex species by multiplying $H(X)$ by $T_{\text {nd }}$. For our 22 species, this multiplication has only small effects on the relative positions in the social ranking; $H(X)_{\mathrm{t}}$ and $S C_{\mathrm{d}}$ are highly correlated $\left(r_{\mathrm{s}}=0.92, P<.001\right)$. Only Spermophilus columbianus, generally considered to be moderately social (Armitage 1981; Michener 1983), markedly increased its social ranking as a consequence of incorporating $T_{\text {nd }}$ into the calculation of $S C_{\mathrm{d}}$. Thus, this multiplication acknowledges, and emphasizes, the potential importance of kin structure. We log-transformed all values for analysis. Our measure of social complexity calculated from demographic data, $S C_{\mathrm{d}}$, was

$$
S C_{\mathrm{d}}=\log \left[\left(H(X)_{\mathrm{t}}\right) T_{\text {nd }}\right] .
$$

An information theory approach emphasizes intraspecific variation when defining social variability. This makes sense intuitively: species for which there is variation in the number of possible age/sex classes living together must be more socially flexible than those in which the number of age/sex classes living together remains fixed. For many social species, social flexibility is the norm (Lott 1991). Moreover, variability is the essence of what is typically emphasized in discussions of complexity (McShea 1981). Theoretically, emphasizing variation can lead to the strange result in which a demographic role (e.g., adult females) in which half the animals lived alone and the other half lived with one other animal would have the same $H(X)$ as a species in which half the individuals lived with five animals and the other half lived with 10 animals. This appeared not to be a problem in our sciurid data set.

At some point in the future, we may be able to define roles according to dominance status or according to types of affiliative behaviors or relationships between animals (e.g., Lee 1994). Presently, comparative data are lacking to do so, and we resorted simply to defining age/sex roles. This categorization provides an estimate of the types of social interactions possible; social interactions must emerge from animal grouping patterns (e.g., an asocial species does not allogroom much). Because demographic data were often lacking on sex ratios of subadults, only adults had two roles; juveniles, yearlings (when present), and 2yr-olds (when present) had a single role each.

\section{Communicative Complexity}

Information theory can explicitly be used to describe and quantify communicative complexity. Unfortunately, to use information theory properly, we must study both the production and perception of signals; not all forms of acoustic variation may be perceptually salient (e.g., Green and Marler 1979; Hauser 
1996). Information on both the production and perception of signals is practically unavailable for the vast majority of species and only for a few sciurids. Thus, we use repertoire size, a variable more amenable to comparative study, as a first approximation of communicative complexity. We focused on alarm call repertoire size.

When alarmed by predators, many species produce specific vocalizations (Klump and Shalter 1984). We believe that alarm call repertoire size is an ideal system to study the relationship between social and communicative complexity for the following reasons. First, alarm calls are social calls. Alarm calling may increase direct or indirect fitness components (e.g., Dunford 1977b; Sherman 1977; Schwagmeyer 1980; Shields 1980; Blumstein et al. 1997), and thus social complexity may drive the evolution of alarm call complexity.

Second, ground-dwelling sciurid alarm calls tend to be loud and obvious; thus, counts of alarm repertoire size should not be biased toward the betterstudied species. In contrast, those species studied in captivity and/or those species well studied in the field are routinely reported to produce more nonalarm vocalizations than less well studied species (e.g., Waring 1970). Nonalarm vocalizations tend to be quieter and are often less obvious to observers (D. T. Blumstein, personal observations). This systematic bias that prevents a meaningful comparison of ground-dwelling sciurid total repertoire size is not present when comparing alarm repertoire size.

Third, each alarm call tends to be a relatively short duration vocalization that primarily functions on an immediate timescale to potentially alert conspecifics (e.g., Sherman 1977; Schwagmeyer 1980; but see Schleidt 1973; Owings and Hennessy 1984; Loughry and McDonough 1988; D. T. Blumstein, unpublished data, for examples of calls functioning on a longer timescale). In contrast, many songbirds combine unique acoustic elements into more elaborate songs that function on a longer timescale and for different functions. For instance, bird songs may identify territories, signal readiness to mate, and so forth (Catchpole and Slater 1995). When acoustic elements are combined to function on a longer timescale, it is much more difficult to estimate repertoire size (Kroodsma 1982).

Fourth, while social signals used in other situations should logically co-vary with social complexity (e.g., aggressive and/or submissive signals), many of these signals are multimodal (e.g., an aggressive dog may growl and erect its hair), and it is difficult simply to describe multimodal signal (their systematic study is in its relative infancy; see, e.g., Hughes 1996). Moreover, while olfactory signals may be an important component of multimodal signals, estimating the size of an olfactory repertoire is difficult. Because alarm calls are loud and obvious acoustic signals, estimates of repertoire size should be less biased.

Finally, whereas environmental experience influences song repertoire size in several bird families, repertoire size in mammals seems much less plastic (e.g., Snowdon 1982; Snowdon and Elowson 1992; Hauser 1996), and there is no evidence that any species learns its alarm calls. Together, these factors make mammalian alarm calls make an ideal system to study the relationship between social and communicative complexity.

Some species vary calls according to the degree of risk the caller experi- 
ences-perhaps according to the response urgency, or the imminence of predation that the caller faces (Robinson 1981; Owings and Hennessy 1984; Blumstein 1995a; Blumstein and Armitage 1997). In addition, some species vary call structure according to the type of predator detected (Seyfarth et al. 1980; Davis 1984; Cheney and Seyfarth 1990; Marler et al. 1992; Macedonia and Evans 1993). Identifying predator-specific calls is important, for it was generally assumed that only humans could communicate about events and stimuli external to themselves; nonhumans supposedly only communicated about their internal states (reviewed in Marler 1985; Hauser 1996). Regardless of whether calls are predator specific or not, both types of variable alarm calls are referred to as situationally specific in that call structure in some way varies according to situation.

Repertoire size should limit the degree to which risk or predator type can be specified. Thus, repertoire size should be associated with the potential benefits an individual hearing a given alarm call can gain by hearing that call. For instance, if a species has an "eagle" call and a "fox" call, an individual hearing an eagle call "knows" that there is a predator in the air and thus may take appropriate action. In contrast, for species that communicate the degree of risk a caller experiences, a "high-risk" call initially conveys information only about the caller's perception of risk. Thus, a perceiver would presumably require additional contextual information (Leger 1993) — such as the caller's location, the caller's age, the caller's identity, or the caller's concomitant behavior - to interpret properly the degree of risk the caller experienced and thus the degree of risk the perceiver may experience. It is likely that more complex kin-structured social systems will select for more complex alarm communication. Specifically, we predict that social complexity will select for larger repertoire size because larger repertoires permit situational variation to be more precisely specified.

\section{METHODS}

\section{The Data Set}

We reviewed the literature for studies that reported demographic information and for studies that discussed alarm communication. A number of studies did not report litter size distribution. If a mean and standard deviation were reported, we assumed litter size was normally distributed to estimate litter size distribution. We either chose the single best demographic data set (e.g., Hoogland 1995) or combined several studies. When different studies contributed demographic data, we weighted the average by sample size. We counted the number of discrete call types to calculate alarm call repertoire size. Our counts may overestimate call repertoire size for species in which call types continuously graded into each other, if and when previous investigators reported continuously varying calls as discrete call types. Our counts may underestimate call repertoire size for species that vary the acoustic microstructure of their calls with predator type (e.g., C. Slobodchikoff, personal communication; see the double-daggered note 
TABLE 1

Final Comparative Data Set and Sources Consulted

\begin{tabular}{lccccc}
\hline \hline Species & $T_{\mathrm{nd}}$ & $H(X)_{\mathrm{t}}$ & $S C_{\mathrm{d}}$ & $N \mathrm{AC}$ & References Consulted* \\
\hline Marmota flaviventris & 2 & 5.70 & 1.06 & $2 \dagger$ & $1-5$ \\
Marmota caligata & 3 & 7.42 & 1.35 & 4 & $6-9,17$ \\
Marmota olympus & 3 & 9.62 & 1.46 & 4 & 10,17 \\
Marmota camtschatica & 3 & 4.18 & 1.10 & 1 & $11-13$ \\
Marmota monax & 1 & 1.88 & .27 & 1 & $14-17,78,79$ \\
Marmota caudata & 3 & 5.59 & 1.22 & 1 & $17-20$ \\
Marmota marmota & 3 & 8.57 & 1.41 & 2 & $21-26$ \\
Cynomus ludovicianus & 2 & 6.60 & 1.12 & 1 & 30,31 \\
Cynomus parvidens & 2 & 8.52 & 1.23 & 1 & $29,32-34$ \\
Cynomus gunnisoni & 2 & 5.32 & 1.03 & $1 \ddagger$ & 29,35 \\
Cynomus leucurus & 1 & 6.84 & .84 & 1 & $36-40$ \\
Spermophilus tereticaudus & 1 & 3.00 & .48 & 1 & $41-48$ \\
Spermophilus tridecemlineatus & 1 & 3.16 & .50 & 1 & $49-51$ \\
Spermophilus lateralis & 1 & 2.39 & .38 & 2 & $52-55$ \\
Spermophilus beecheyi & 1 & 1.83 & .26 & $2 \S$ & $56-60$ \\
Spermophilus variegatus & 1 & 2.67 & .43 & 2 & $61-63$ \\
Spermophilus armatus & 1 & 2.76 & .44 & 2 & $64-66$ \\
Spermophilus beldingi & 1 & 2.52 & .40 & 2 & 67,68 \\
Spermophilus richardsonii & 1 & 2.45 & .39 & 3 & $67-70$ \\
Spermophilus elegans & 1 & 2.70 & .43 & 2 & $67,71-74$ \\
Spermophilus columbianus & 2 & 2.23 & .65 & 3 & $75-77$ \\
Spermophilus townsendii & 1 & 2.55 & .41 & 2 & \\
\hline
\end{tabular}

Note.-Variables: $T_{\mathrm{nd}}=$ the time to natal dispersal where $1=$ disperses during first active season or before first hibernation, 2 = disperses during the second active season or before second hibernation, and $3=$ disperses after second active season/hibernation; $H(X)_{\mathrm{t}}=$ sum of $H(X)$ for each demographic "role" present; $S C_{\mathrm{d}}=$ our measure of social complexity calculated from demographic data; and $N \mathrm{AC}$ $=$ the number of alarm calls.

* 1, K. B. Armitage, unpublished data; 2, Armitage 1991; 3, Frase and Hoffmann 1980; 4, Blumstein and Armitage 1997; 5, Waring 1966; 6, Barash 1974; 7, Barash 1980; 8, Holmes 1979; 9, Holmes 1984; Barash 1973; 11, Kapitonov 1963 cited in Rausch and Rausch 1971; 12, Mosolov and Tokarsky 1994; 13, Ognev [1947] (1963); 14, de Vos and Gillespie 1960; 15, Ferron an Ouellet 1989; 16, Meier 1985; 17, D. T. Blumstein, unpublished data; 18, Blumstein and Arnold, in press; 19, Blumstein 1995a; 20, Blumstein 1995b; 21, Arnold 1993a; 22, Arnold 1993b; 23, Barash 1976; 24, Blumstein and Arnold 1995; 25, Perrin et al. 1993b; 26, Perrin et al. 1993a; 27, Hoogland 1995; 28, King 1955; 29, Waring 1970; 30, Pizzimenti and Collier 1975; 31, Wright-Smith 1978; 32, Fitzgerald and Lechleitner 1974; 33, Rayor 1985; 34, Rayor 1988; 35, L. Cooke, personal communication to K. B. Armitage; 36, Dunford 1977b; 37, Dunford 1977c; 38, Dunford 1977a; 39, Ernest and Mares 1987; 40, Reynolds and Turkowski 1972; 41, Matocha 1977; 42, McCarley 1966; 43, Rongstad 1965; 44, Schwagmeyer 1980; 45, Schwagmeyer and Brown 1981; 46, Schwagmeyer and Brown 1983; 47, Streubel and Fitzgerald 1978; 48, Wistrand 1974; 49, Bartels and Thompson 1993; 50, Hatt 1927; 51, Phillips 1981; 52, Evans and Holdenreid 1943; 53, Fitch 1948; 54, Leger et al. 1980; 55, Owings et al. 1977; 56, Krenz 1977; 57, Oaks et al. 1987; 58, Ortega 1990; 59, Ortega 1991; 60, Shriner and Stacey 1991; 61, Balph and Balph 1966; 62, Balph and Stokes 1963; 63, Slade and Balph 1974; 64, Morton and Gallup 1975; 65, Robinson 1981; 66, Turner 1973; 67, Koeppl et al. 1978; 68, Michener 1979; 69, Pfeiffer 1982; 70, Zegers 1984; 71, Betts 1976; 72, Festa-Bianchet and King 1991; 73, Harris et al. 1983; 74, Zammuto and Millar 1985; 75, Smith and Johnson 1985; 76, Rickart 1986; 77, Rickart 1987; 78, Hamilton 1934; 79, Lloyd 1972.

$\dagger$ Yellow-bellied marmots produce three vocalizations in potentially alarming situations but only two of them (whistles and trills) are loud alarm calls (Blumstein and Armitage 1997). Moreover, the quiet call (chucks), when played back, does not elicit an alarm response in conspecifics. For these analyses, we scored yellow-bellied marmots as having two-alarm vocalizations.

* The microstructure (specifically, the shape of certain harmonics) of Gunnison prairie dog alarm barks co-varies with predator species (C. Slobodchikoff, personal communication) and with the identity of some individual predators (Slobodchikoff et al. 1991). It is interesting that variation appears continuous: for this analysis, we scored Gunnison prairie dogs as having a single-alarm vocalization (barks).

$\S$ Owings and Leger (1980) found microstructural predator and social specificity in California ground squirrels' chatter vocalization, and Leger et al. (1980) found microstructural variation in socially elicited single-note vocalizations. For this analysis, we scored California ground squirrels as having two alarm vocalizations: chatters and single-note vocalizations. 
in table 1). Because not all species were studied with equivalent detail, we focused on the number of discrete alarm call types.

\section{Regression Analyses}

We regressed our measure of social complexity against alarm call repertoire size where we set the $y$-intercept to 1.0 because all species had at least one alarm call and we expected repertoire size to increase with complexity. To control for possible phylogenetic nonindependence on alarm repertoire size and on sociality, we examined the relationship using standardized independent contrasts calculated for each variable. We used Purvis and Rambaut's (1995) statistical package, CAIC, to calculate independent contrasts for social complexity and alarm call repertoire size. As specified in the CAIC manual, we regressed these standardized contrasts through the origin. In all cases, we used one-tailed tests because we have a specific directional hypothesis.

There is no published phylogenetic hypothesis that includes all species of interest, and different species groups have been studied at various degrees of detail. We eagerly anticipate the publication of inclusive and well-supported phylogenetic hypotheses. In their absence, we generally inferred phylogeny from taxonomy (Nowak and Paradiso 1983) but added additional information where known (Howell 1915; Hoffmann and Nadler 1968 for the marmots; Hafner 1984 for sciurid subgenera), and we refer to this tree as tree 1 (fig. 1). Black (1972) assumed that the genus Marmota evolved in the New World from a woodchucklike ancestor. We switched the location of Marmota marmota and Marmota monax to create tree 2 (fig. 1). Thomas and Martin (1993) questioned the ancestral location of the genus Marmota. They suggested the genus Marmota evolved recently from Spermophilus ancestors. We calculated independent contrasts from a tree, tree 3 (fig. 1), in which Cynomys, Marmota, and the remaining Spermophilus subgroups branch simultaneously, and a tree, tree 4 (fig. 1), that reflects the recent origin of marmots. We generated tree 5 (fig. 1) to recognize evidence suggesting Cynomys is the crown group of the subgenus Spermophilus in the currently recognized genus Spermophilus (Dobson 1985 and references therein; Goodwin 1990).

To calculate standardized independent contrasts, we set all branch lengths equal and selected the crunch option in CAIC. Setting branch lengths equal assumes an underlying evolutionary model of punctuational change (e.g., Harvey and Pagel 1991) and is less inaccurate than estimating branch lengths with missing species (Purvis and Rambaut 1995). No independent measures of branch length are available for our partial phylogenies, so we did not calculate contrasts assuming Brownian motion trait evolution.

There was variation in the repertoire size of marmots and ground squirrels but not prairie dogs (Results). For marmots alone and for ground squirrels alone, we regressed social complexity against alarm call repertoire size and reran regressions on independent contrasts calculated from the relevant trees (two trees for marmots and four trees for squirrels). Finally, because the squirrel distinction may be artificial (e.g., Dobson 1985), we reran regressions with a data set containing Cynomys and Spermophilus. 


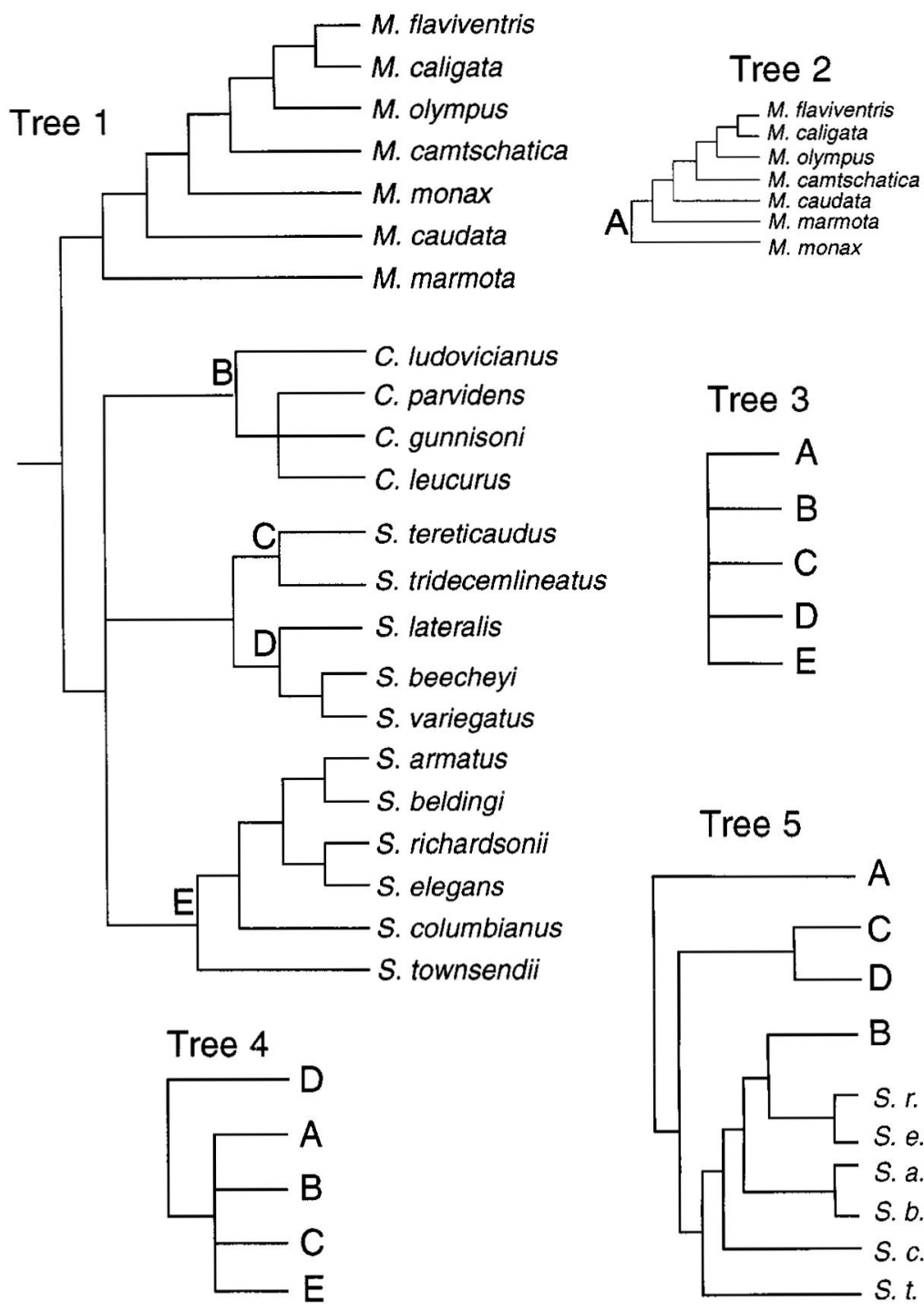

FIG. 1.-Phylogenetic hypotheses used to calculate contrasts. These are partial working phylogenies of sciurid rodents; recognized genera and species not included in these analyses are not illustrated. Tree 1, A taxonomically derived tree with phylogenetic information added where known. Tree 2, Marmota monax shifted to reflect its possible ancestral location in Marmota. Letters marked at higher nodes on trees 1 and 2 are used to illustrate the structure of the following two trees. Tree 3, An unresolved origin of Marmota. Tree 4, A recent origin of Marmota and other sciurids from a subgroup of species currently classified as Spermophilus. Tree 5, Cynomys as the crown group of the subgenus Spermophilus. 
In addition to calculating independent contrasts, we also analyzed the data using phylogenetic autocorrelation (Cheverud et al. 1985; Gittleman and Kot 1990; Gittleman and Luh 1992). Phylogenetic autocorrelation permitted us to estimate and statistically remove the maximum amount of variation in each variable (social complexity, repertoire size) that could be explained by phylogenetic similarity. Phylogenetic autocorrelation assumes explicitly statistical models of trait change that vary according to an autoregressive model (Purvis et al. 1994; Martins 1995) and, under a Brownian motion model of evolution, may produce erratic results with sample sizes $<40$ (Martins 1996). We used a single phylogenetic hypothesis, the taxonomy reported in Nowak and Paradiso (1983), to estimate the phylogenetic distance matrix. The phylogenetic distance matrix defines the sets of species with which each individual species' trait value will be compared to search for autocorrelation. The classical taxonomic classification recognizes subgenera in both Cynomys and Spermophilus and recognizes two subtribes: one containing Marmota and the other containing both Cynomys and Spermophilus. We used the program P.A. (Luh et al. 1995) to fit phylogenetic autocorrelations. Correlograms (plots of Moran's I-the autocorrelation statistic-vs. phylogenetic distance) suggested significant phylogenetic autocorrelation at lower taxonomic levels that disappeared after we calculated phylogenyfree residuals. We regressed the phylogeny-free residuals against each other to estimate the variation in alarm repertoire size independently explained by social complexity.

\section{RESULTS}

Our final comparative data set contained data for 22 species: seven of 14 marmots (three Old World, four New World), four of five prairie dogs (a New World genus), and 11 of 38 ground squirrels (all were New World species; table $1)$. Our metric of social complexity was highly correlated with two previous indexes of sciurid sociality $(r=0.84, N=17$ [Armitage 1981]; $r=0.89, N=17$ [Michener 1983]). Nevertheless, there are some discrepancies with less objective assessments of social complexity. For instance, J. Hoogland (personal communication) noted that our demography-based metric classified black-tailed prairie dogs (Cynomys ludovicianus) as less complex than Utah prairie dogs (Cynomys parvidens). His detailed behavioral observations suggest that black-tailed prairie dogs engaged in more types of social behavior than Utahs. It is interesting that many of black-tailed prairie dogs' social interactions during the time before pups emerge are related to perpetrating or preventing infanticide. It would be interesting to study the relationship between social complexity and the amount and/or degree of amicable behaviors. Despite this exception (black-tailed vs. Utah prairie dogs), our metric generally is consistent with our expectations based on previous studies.

Social complexity varied between genera (Kruskal-Wallis $P=.004$ ). Post hoc multiple comparisons $(P<.05)$ suggested marmots and prairie dogs were more complex than ground squirrels. Alarm call repertoire size tended to vary between genera (Kruskal-Wallis $P=.055$ ); prairie dogs had significantly fewer 


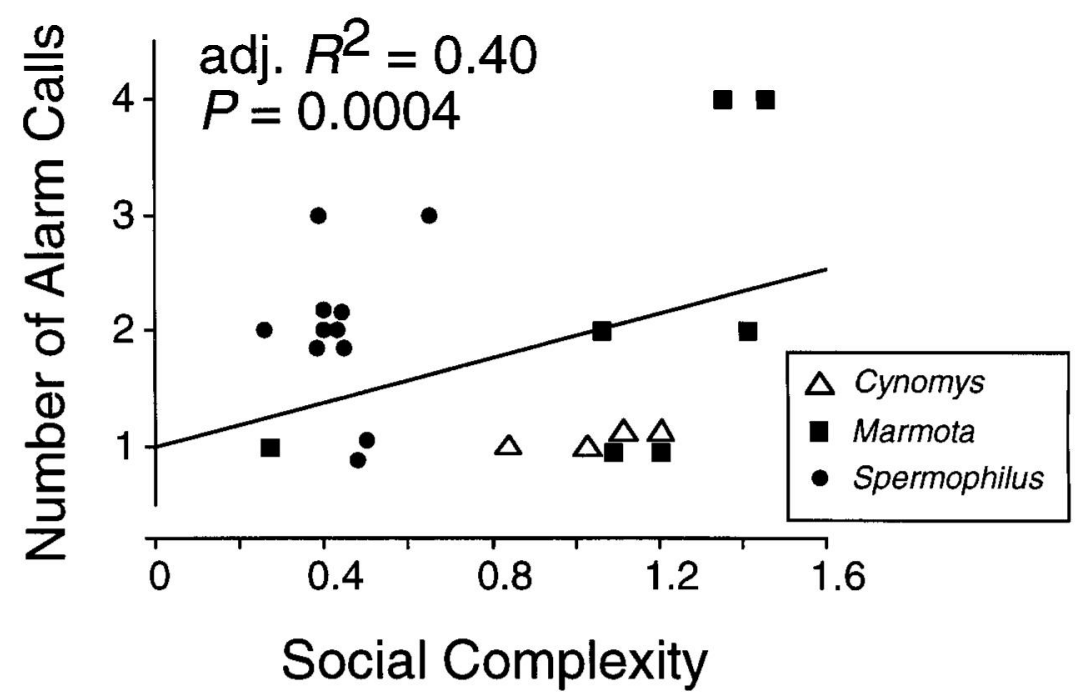

FIG. 2.-The relationship between social complexity and alarm call repertoire size. Because all species had at least one alarm call, we set the $y$-intercept at 1 . Overlapping values are vertically offset; the $P$ value is one-tailed.

TABLE 2

Variation in Alarm Call Repertoire Size Explained by Social Complexity (adjusted $R^{2}$ ) Assuming Five Different Evolutionary Scenarios

\begin{tabular}{lccccc}
\hline \hline & Tree 1 & Tree 2 & Tree 3 & Tree 4 & Tree 5 \\
\hline All data & $6.5^{*}$ & $7.9^{*}$ & $11.9^{*}$ & $10.6^{*}$ & $30.6^{\dagger}$ \\
No woodchucks & $3.8 \mathrm{NS}$ & $5.1^{*}$ & $5.2 \mathrm{NS}$ & $10.4^{*}$ & $20.5^{* *}$ \\
Marmots only & $17.3^{*}$ & $18.5^{*}$ & $\ldots$ & $\ldots$ & $\ldots$ \\
$\quad$ Marmots without woodchucks & $77.7 \dagger$ & $73.6 \dagger$ & $\ldots$ & $\ldots$ & $\ldots$ \\
Squirrels only & $0 \mathrm{NS}$ & $0 \mathrm{NS}$ & $0 \mathrm{NS}$ & $0 \mathrm{NS}$ & $\ldots$ \\
Cynomys and Spermophilus & $\cdots$ & $\ldots$ & $\ldots$ & $\ldots$ & $0 \mathrm{NS}$ \\
\hline
\end{tabular}

Note.-NS $=P>.1$ (one-tailed).

$* .1>P>.05$ (one-tailed).

$* * .05>P>.01$ (one-tailed).

$\dagger .01>P>.001$ (one-tailed).

vocalizations than did either marmots or ground squirrels. About $40 \%$ of the variation in alarm repertoire size was significantly explained (adjusted $R^{2}=$ $0.40, P=.0004$ ) by $S C_{\mathrm{d}}$, our measure of social complexity (fig. 2). After controlling for possible phylogenetic effects by calculating independent contrasts, we found that social complexity explained less variation in alarm call repertoire size (table 2). Under some evolutionary scenarios, no significant variation in repertoire size was significantly explained by social complexity. Regression on phylogeny-free residuals calculated from the phylogenetic autocorrelation analy- 
sis generated positive results; once again, less variation was explained after removing phylogenetic effects (adjusted $R^{2}=11.6, P=.031$ ).

Woodchucks (Marmota monax) were an outlier that had a large impact on some results of the phylogenetic analyses. Woodchucks are a marmot with a simple social system and apparently a single, two-part alarm call (Hamilton 1934; Lloyd 1972; Meier 1985). We have been trying to study woodchuck alarm communication in detail to no avail: in over $100 \mathrm{~h}$ of fieldwork on woodchuck alarm communication, not a single alarm call was heard (D. T. Blumstein, unpublished data). Given some uncertainty about the number of alarm vocalizations woodchucks produce (one or two), we removed woodchucks from the analysis and recalculated all contrasts. Removing woodchucks reduced the amount of explained variation (table 2).

When marmots and squirrels (prairie dogs do not have variable numbers of alarm vocalizations) were analyzed separately, results were similar. About 54\% of the variation in marmot repertoire size was explained by our measure of social complexity $(P=.01)$, and significant variation was explained after calculating independent contrasts to control for phylogenetic effects under some evolutionary scenarios (table 2). When we examined the effect of social complexity on alarm repertoire size in marmots alone, removing woodchucks greatly increased explained variation. About $69 \%$ of the variation in ground squirrel repertoire size was explained by social complexity $(P=.0003)$, while no significant variation was explained after controlling for potential phylogenetic similarity using independent contrasts given any of the evolutionary scenarios. Finally, when we combined Cynomys and Spermophilus, about $18 \%$ of the variation in repertoire size was explained in the raw data set $(P=.0293)$, while no significant variation was explained in the contrast-based analysis (table 2 ). The phylogenetic autocorrelation estimated that $54 \%$ of the variation in social complexity was attributable to phylogenetic (specifically taxonomic) similarity, while only $4 \%$ of the variation in alarm call repertoire size in analyses that included woodchucks and $6 \%$ of the variation in analyses that excluded woodchucks were attributed to phylogenetic similarity. Thus, substantial variation in alarm call repertoire size remained unexplained and was potentially available for adaptive coevolution with social complexity.

\section{DISCUSSION}

Complex social behavior explained some, but not most, of the variation in alarm repertoire size in sciurid rodents. Because both vocalizations (e.g., Nikolskii 1976; Macedonia and Stanger 1994; but see Nottebohm 1975; Irwin 1990) and social behavior (e.g., Edwards and Naeem 1993; Di Fiore and Rendall 1994; Prum 1994; Chan 1996; but see Gittleman et al. 1996) may have substantial phylogenetic information, we adjusted for and/or removed the effects of phylogenetic similarity. Given some uncertainty in historical relationships, we examined several alternative phylogenetic hypotheses. The specific hypothesis we used influenced the amount of explained variation, but the general relationship remained positive. When we examined subsets of the full data set, we found that 
after accounting for phylogeny, social complexity may (in Marmota) or may not (in Spermophilus and Cynomys) be an important determinant of communicative complexity. Closely related squirrels tended to have similar numbers of alarm calls, and there is relatively limited variation in both $S C_{\mathrm{d}}$ and the number of alarm calls to explain. In contrast, marmots had the most variation in both $S C_{\mathrm{d}}$ and the number of alarm calls to be potentially explained.

If social behavior is not the primary determinant of alarm repertoire size in sciurids, what else might be responsible for the evolution of complex communication? At least four factors other than sociality may generally influence the evolution of complex communication and specifically influence the evolution of alarm call complexity. We do not suggest that these (and potentially other) factors are equally important in the evolution of complex communication. However, they might explain additional unexplained variation in communicative complexity.

Variation in the facial or laryngeal morphology may constrain or permit the production of variable alarm calls or other vocalizations (Fitch and Hauser 1995; Hauser 1996). While this may account for variation among genera, within a genus animals appear superficially similar. Detailed morphological studies ultimately need to determine whether there are differences within or between genera. As a first approximation, one reason to study communicative complexity in sciurids is the ability to discount the importance of within-genus morphological variation.

Physical and/or biological habitat acoustics may directly influence communicative complexity and may also interact with social behavior. Sounds must be transmitted through space during which time they may degrade in several ways and/or attenuate (Morton 1975; Wiley and Richards 1978; Brown and Waser 1988; Forrest 1994). In particularly destructive environments, effective communication may have to be simple. If habitat structure precludes differentiation of two sounds from each other at a distance (e.g., marmot example in Blumstein and Daniel, in press), the physical habitat has effectively selected for relatively simple communication. The biological habitat may be defined as the suite of other vocally communicating animals. With others present, available "bandwidth" may be limited and acoustic structure may be constrained (Ryan 1988). Competition with other conspecifics may select for greater acoustical structural variation (Alexander 1960). Both forms of habitat acoustics may interact with social behavior. Certain physical environments may have certain types or distributions of resources and may favor certain social systems (Wittenberger 1981). If certain types of habitats also have specific acoustics, then effective communication may require individuals to clump. Animals living in habitats with considerable acoustic competition may also compete with heterospecifics for bandwidth in which to communicate (Ryan 1988). Alternatively, mutualistic alarm-calling relationships with other species (e.g., Waring 1966; Rasa 1983; Seyfarth and Cheney 1990) may influence the costs and benefits of associating with other conspecifics and may constrain acoustic variation.

Finally, specific needs may influence communicative complexity and/or interact with social behavior. For instance, one compelling hypothesis for the evolu- 
tion of predator-specific alarm calls is that species with fundamentally different predator-specific escape strategies will benefit most from predator-specific calls (Macedonia and Evans 1993). For example, vervet monkeys (Cercopithicus aethiops) produce acoustically different calls in response to different types of predators; they chutter to snakes, bark to leopards, and cough to eagles (Cheney and Seyfarth 1990). Monkeys hearing chutters immediately stand bipedally and look for snakes, those hearing barks climb trees and retreat to the distal part of limbs where they will be safe from leopards, and those hearing coughs retreat to the center of trees where they are safe from eagles. Macedonia and Evans (1993) predicted that species with predator-specific escape strategies, like vervet monkeys, will have predator-specific alarm calls. Because there is variation in sciurid predators, some species may have predator-specific escape strategies, and the incompatibility of these strategies may be associated with larger repertoire sizes. However, because most ground-dwelling sciurids flee to a burrow when alarmed, their behavior may reduce selection for predator-specific escape strategies. The need to avoid predators may influence how conspecifics are distributed in space, which in turn may influence social behavior.

More data and better phylogenetic resolution will likely permit a more exact estimate of the variation in alarm call repertoire size explained by social complexity. Yet because alarm repertoires may be simultaneously influenced by several other causal factors, future analyses should simultaneously study the relative importance of these other factors. Thus, we suggest the question be rephrased: How important is social complexity, relative to other causal factors, for the evolution of communicative complexity?

Current evidence suggests the genus Marmota may offer a good opportunity for future research. The relationship between alarm call repertoire size and social complexity is significant when controlling for phylogenetic effects. Marmots vary in both alarm call repertoire size and in $S C_{\mathrm{d}}$ more than either ground squirrels or prairie dogs. Thus, we suggest that studying additional species of marmots is an efficient way to address the question of the relative importance of social complexity and other causal factors in the evolution of complex communication. Alternatively, another research agenda might focus on the currently recognized genus Spermophilus because there is a relatively high alarm call complexity in spite of limited social complexity. Thus, it should be possible to identify factors other than sociality that influence communicative complexity.

In the future, we hope investigators will publish more specific data on age/ sex distributions of other taxa to permit the study of complexity in other taxa. However, many socioecological questions are studied by comparing populations of a single species living in different ecological settings. While we used our metric of complexity to study variation among species, future investigators could use it to study intraspecific variation in complexity.

\section{ACKNOWLEDGMENTS}

We thank R. Jander for encouraging us to explore nontraditional uses of information theory; J. Daniel for help collecting what turned out to be very impor- 
tant data on Olympic and hoary marmot alarm communication; B. Crespi, M. Greenfield, J. Losos, E. Martins, R. Prum, and J. Stamps for discussions about comparative analyses and/or communication; R. Hoffmann for sharing unpublished phylogenetic hypotheses; S. Dobson for discussing comparative sciurid work in progress and discussing alternative phylogenetic hypotheses; J. Gittleman, H. Luh, E. Martins, D. Miles, and A. Purvis for sharing phylogenetic analysis software with us; B. Crespi, S. Dobson, M. Hauser, J. Hoogland, J. Macedonia, B. Roitberg, and two anonymous reviewers for very helpful comments on previous versions of the article; and J. Kingsolver and B. Roitberg for giving us a second chance. D.T.B. was supported by a National Institute of Health postdoctoral fellowship (NRSA MH10793).

\section{LITERATURE CITED}

Alexander, R. D. 1960. Sound communication in Orthoptera and Cicadidae. Pages 38-92 in W. E. Lanyon and W. N. Tavolga, eds. Animal sounds and communication. American Institute of Biological Science, Washington, D.C.

$\rightarrow$. 1974. The evolution of social behavior. Annual Review of Ecology and Systematics 5: $325-383$.

Armitage, K. B. 1981. Sociality as a life-history tactic of ground squirrels. Oecologia (Berlin) 48: $36-49$.

1991. Social and population dynamics of yellow-bellied marmots: results from long-term research. Annual Review of Ecology and Systematics 22:379-407.

Arnold, W. 1993a. Energetics of social hibernation. Pages 65-80 in C. Carey, G. L. Florant, B. A. Wunder, and B. Horwitz, eds. Life in the cold: ecological, physiological, and molecular mechanisms. Westview, Boulder, Colo.

- $1993 \mathrm{~b}$. Social evolution in marmots and the adaptive value of joint hibernation. Verhandlungen der Deutschen Zoologischen Gesellschaft 86:79-93.

Balph, D. F., and A. W. Stokes. 1963. On the ethology of Uinta ground squirrels. American Midland Naturalist 69:106-126.

Balph, D. M., and D. F. Balph. 1966. Sound communication of Uinta ground squirrels. Journal of Mammalogy 47:440-450.

Barash, D. P. 1973. The social biology of the Olympic marmot. Animal Behaviour Monographs 6: 173-245.

$\rightarrow$. 1974. The social behavior of the hoary marmot (Marmota caligata). Animal Behaviour 22: 256-261.

$\rightarrow-1976$. Social behaviour and individual differences in free-living alpine marmots (Marmota marmota). Animal Behaviour 24:27-35.

$\rightarrow$ - 1980. The influence of reproductive status on foraging by hoary marmots (Marmota caligata). Behavioral Ecology and Sociobiology 7:201-205.

1989. Marmots: social behavior and ecology. Stanford University Press, Stanford, Calif.

$\rightarrow$ Bartels, M. A., and D. P. Thompson. 1993. Spermophilus lateralis. Mammalian Species 440:1-8.

$\rightarrow$ Betts, B. J. 1976. Behaviour in a population of Columbian ground squirrels, Spermophilus columbianus columbianus. Animal Behaviour 24:652-680.

Bibikow, D. I. 1996. Die Murmeltiere der Welt. Die Neue Brehm-Bucherei Bd. 388. Spektrum Akademischer, Heidelberg.

Black, C. C. 1972. Holarctic evolution and dispersal of squirrels (Rodentia: Sciuridae). Evolutionary Biology 6:305-322.

Blumstein, D. T. 1995a. Golden-marmot alarm calls. I. The production of situationally specific vocalizations. Ethology 100:113-125. 
1995b. Golden-marmot alarm calls. II. Asymmetrical production and perception of situationally specific vocalizations? Ethology 101:25-32.

Blumstein, D. T., and K. B. Armitage. 1997. Alarm calling in yellow-bellied marmots. I. The meaning of situationally variable alarm calls. Animal Behaviour 53:143-171.

$\rightarrow$ Blumstein, D. T., and W. Arnold. 1995. Situational-specificity in alpine-marmot alarm communication. Ethology 100:1-13.

—. In press. Ecology and social behavior of golden marmots (Marmota caudata aurea). Journal of Mammalogy.

Blumstein, D. T., and J. C. Daniel. In press. Inter- and intraspecific variation in the acoustic habitats of three marmot species. Ethology.

$\rightarrow$ Blumstein, D. T., J. Steinmetz, K. B. Armitage, and J. C. Daniel. 1997. Alarm calling in yellow-bellied marmots. II. The importance of direct fitness. Animal Behaviour 53:173-184.

Bonner, J. T. 1988. The evolution of complexity. Princeton University Press, Princeton, N.J.

Brown, C. H., and P. M. Waser. 1988. Environmental influences on the structure of primate vocalizations. Pages 51-66 in D. Todt, P. Goedeking, and D. Symmes, eds. Primate vocal communication. Springer, Berlin.

Catchpole, C. K., and P. J. B. Slater. 1995. Bird song: biological themes and variations. Cambridge University Press, Cambridge.

Chan, L. K. W. 1996. Phylogenetic interpretations of primate socioecology: with special reference to social and ecological diversity in Macaca. Pages 324-360 in E. P. Martins, ed. Phylogenies and the comparative method in animal behavior. Oxford University Press, Oxford.

Cheney, D. L., and R. M. Seyfarth. 1990. How monkeys see the world. University of Chicago Press, Chicago.

$\rightarrow$ Cheverud, J. M., M. M. Dow, and W. Leutenegger. 1985. The quantitative assessment of phylogenetic constraints in comparative analyses: sexual dimorphism in body weights among primates. Evolution 39:1335-1351.

$\rightarrow$ Clutton-Brock, T. H., and P. H. Harvey. 1977. Primate ecology and social organization. Journal of Zoology (London) 183:1-39.

$\rightarrow$ Cole, B. J. 1985. Size and behavior in ants: constraints on complexity. Proceedings of the National Academy of Sciences of the USA 82:8548-8551.

Crespi, B. J. 1996. Comparative analysis of the origins and losses of eusociality: causal mosaics and historical uniqueness. Pages 253-287 in E. P. Martins, ed. Phylogenies and the comparative method in animal behavior. Oxford University Press, Oxford.

Croft, D. B. 1989. Social organization of the Macropodoidea. Pages 505-525 in G. Grigg, P. Jarman, and I. Hume, eds. Kangaroos, wallabies and rat-kangaroos. Surrey Beatty, Chipping Norton, New South Wales.

$\rightarrow$ Crook, J. H., and J. S. Gartlan. 1966. Evolution of primate societies. Nature (London) 210:1200-1203.

$\rightarrow$ Davis, L. S. 1984. Alarm calling in Richardson's ground squirrels (Spermophilus richardsonii). Zeitschrift für Tierpsychologie 66:152-164.

Dawkins, R. 1992. Progress. Pages 263-272 in E. F. Keller and E. A. Lloyd, eds. Keywords in evolutionary biology. Harvard University Press, Cambridge, Mass.

de Vos, A., and D. J. Gillespie. 1960. A study of woodchucks on an Ontario farm. Canadian FieldNaturalist 74:130-145.

$\rightarrow$ Di Fiore, A., and D. Rendall. 1994. Evolution of social organization: a reappraisal for primates by using phylogenetic methods. Proceedings of the National Academy of Sciences of the USA 91:9941-9945.

$\rightarrow$ Dobson, F. S. 1985. The use of phylogeny in behavior and ecology. Evolution 39:1384-1388.

$\rightarrow$ Dunford, C. 1977a. Behavioral limitation of round-tailed ground squirrel density. Ecology 58: 1254-1268.

$\rightarrow-1977 b$. Kin selection for ground squirrel alarm calls. American Naturalist 111:782-785.

$\rightarrow \quad$ 1977c. Social systems of round-tailed ground squirrels. Animal Behaviour 25:885-906.

$\rightarrow$ Edwards, S. V., and S. Naeem. 1993. The phylogenetic component of cooperative breeding in perching birds. American Naturalist 141:754-789.

Eisenberg, J. F. 1981. The mammalian radiations. University of Chicago Press, Chicago. 
Eisenberg, J. F., N. A. Muckenhirn, and R. Rudran. 1972. The relation between ecology and social structure in primates. Science (Washington, D.C.) 176:863-874.

Ernest, K. A., and M. A. Mares. 1987. Spermophilus tereticaudus. Mammalian Species 274:1-9.

$\rightarrow$ Evans, F. C., and R. Holdenreid. 1943. A population study of the Beechey ground squirrel in central California. Journal of Mammalogy 24:231-260.

Ferron, J., and J. P. Ouellet. 1989. Temporal and intersexual variation in the use of space with regard to social organization in the woodchuck (Marmota monax). Canadian Journal of Zoology 67: $1642-1649$.

Festa-Bianchet, M., and W. J. King. 1991. Effects of litter size and population dynamics on juvenile and maternal survival in Columbian ground squirrels. Journal of Animal Ecology 60:10771090 .

Fitch, H. S. 1948. Ecology of the California ground squirrel on grazing lands. American Midland Naturalist 39:513-596.

$\rightarrow$ Fitch, W. T., and M. D. Hauser. 1995. Vocal production in nonhuman primates: acoustics, physiology and functional constraints on "honest" advertisement. American Journal of Primatology 37: 191-219.

Fitzgerald, J. P., and R. R. Lechleitner. 1974. Observations on the biology of Gunnison's prairie dog in central Colorado. American Midland Naturalist 92:146-163.

Foley, R. A., and P. C. Lee. 1989. Finite social space, evolutionary pathways, and reconstructing hominid behavior. Science (Washington, D.C.) 243:901-906.

$\rightarrow$ Forrest, T. G. 1994. From sender to receiver: propagation and environmental effects on acoustic signals. American Zoologist 34:644-654.

$\rightarrow$ Frase, B. A., and R. S. Hoffmann. 1980. Marmota flaviventris. Mammalian Species 135:1-8.

$\rightarrow$ Gittleman, J. L., and M. Kot. 1990. Adaptation: statistics and a null model for estimating phylogenetic effects. Systematic Zoology 39:227-241.

$\rightarrow$ Gittleman, J. L., and H.-K. Luh. 1992. On comparing comparative methods. Annual Review of Ecology and Systematics 23:383-404.

Gittleman, J. L., C. G. Anderson, M. Kot, and H.-K. Luh. 1996. Phylogenetic lability and rates of evolution: a comparison of behavioral, morphological and life history traits. Pages 166-205 in E. P. Martins, ed. Phylogenies and the comparative method in animal behavior. Oxford University Press, New York.

Goodwin, H. T. 1990. Systematics, biogeography, and evolution of fossil prairie dogs (genus Cynomys). Ph.D. diss. University of Kansas, Lawrence.

Green, S., and P. Marler. 1979. The analysis of animal communication. Pages 73-158 in P. Marler and J. G. Vandenbergh, eds. Handbook of behavioral neurobiology. Vol. 3. Social behavior and communication. Plenum, New York.

Hafner, D. J. 1984. Evolutionary relationships of the Nearctic Sciuridae. Pages 3-23 in J. O. Murie and G. R. Michener, eds. The biology of ground-dwelling squirrels. University of Nebraska Press, Lincoln.

Hamilton, W. J., Jr. 1934. The life history of the rufescent woodchuck, Marmota monax rufescens Howell. Annals of the Carnegie Museum 23:85-179.

$\rightarrow$ Harris, M. A., J. O. Murie, and J. A. Duncan. 1983. Responses of Columbian ground squirrels to playback of recorded calls. Zeitschrift für Tierpsychologie 63:318-330.

Harvey, P. H., and M. D. Pagel. 1991. The comparative method in evolutionary biology. Oxford University Press, Oxford.

Hatt, R. T. 1927. Notes on the ground squirrel Callospermophilus. Occasional Papers of the Museum of Zoology, University of Michigan 185:1-22.

Hauser, M. D. 1996. The evolution of communication. MIT Press, Cambridge, Mass.

Hinde, R. A. 1975. Interactions, relationships and social structure in non-human primates. Pages 1324 in S. Kondo, M. Kawai, A. Ehara, and S. Kawamura, eds. Proceedings from the symposia of the fifth congress of the international primatological society, Nagoya, Japan, August 1974. Japan Science Press, Tokyo.

$\rightarrow$ Hoffmann, R. S., and C. F. Nadler. 1968. Chromosomes and systematics of some North American species of the genus Marmota (Rodentia: Sciuridae). Experientia 24:740-742. 
Holmes, W. G. 1979. Social behavior and foraging strategies of hoary marmots (Marmota caligata) in Alaska. Ph.D. diss. University of Washington, Seattle.

- 1984. The ecological basis of monogamy in Alaskan hoary marmots. Pages 250-274 in J. O. Murie and G. R. Michener, eds. The biology of ground-dwelling squirrels. University of Nebraska Press, Lincoln.

Hoogland, J. L. 1995. The black-tailed prairie dog: social life of a burrowing mammal. University of Chicago Press, Chicago.

$\rightarrow$ Howell, A. H. 1915. Revision of the American marmots. North American Fauna 37:4-80.

$\rightarrow$ Hughes, M. 1996. The function of concurrent signals: visual and chemical communication in snapping shrimp. Animal Behaviour 52:247-257.

$\rightarrow$ Irwin, R. E. 1990. Directional sexual selection cannot explain variation in song repertoire size in the New World blackbirds (Icterinae). Ethology 85:212-224.

$\rightarrow$ Janson, C. H., and M. L. Goldsmith. 1995. Predicting group size in primates: foraging costs and predation risk. Behavioral Ecology 6:326-336.

King, J. A. 1955. Social behavior, social organization, and population dynamics in a black-tailed prairie dog town in the Black Hills of South Dakota. Contributions of the Laboratory of Vertebrate Biology 67:1-123.

$\rightarrow$ Klump, G. M., and M. D. Shalter. 1984. Acoustic behaviour of birds and mammals in the predator context. I. Factors affecting the structure of alarm signals. II. The functional significance and evolution of alarm signals. Zeitschrift für Tierpsychologie 66:189-205, 206-226.

$\rightarrow$ Koeppl, J. W., R. S. Hoffmann, and C. F. Nadler. 1978. Pattern analysis of acoustical behavior in four species of ground squirrels. Journal of Mammalogy 59:677-696.

Krenz, M. C. 1977. Vocalizations of the rock squirrel (Spermophilus variegatus). M.S. thesis. Texas Tech University, Lubbock.

Kroodsma, D. E. 1982. Song repertoires: problems in their definition and use. Pages 125-146 in D. E. Kroodsma and E. H. Miller, eds. Acoustic communication in birds. Vol. 2. Academic Press, New York.

Lee, P. C. 1994. Social structure and evolution. Pages 266-303 in P. J. B. Slater and T. R. Halliday, eds. Behaviour and evolution. Cambridge University Press, Cambridge.

$\rightarrow$ Leger, D. W. 1993. Contextual sources of information and responses to animal communication signals. Psychological Bulletin 113:295-304.

$\rightarrow$ Leger, D. W., D. H. Owings, and D. L. Gelfand. 1980. Single-note vocalizations of California ground squirrels: graded signals and situation-specificity of predator and socially evoked calls. Zeitschrift für Tierpsychologie 52:227-246.

$\rightarrow$ Lloyd, J. E. 1972. Vocalization in Marmota monax. Journal of Mammalogy 53:214-216.

Lott, D. F. 1991. Intraspecific variation in the social systems of wild vertebrates. Cambridge University Press, Cambridge.

$\rightarrow$ Loughry, W. J., and C. M. McDonough. 1988. Calling and vigilance in California ground squirrels: a test of the tonic communication hypothesis. Animal Behaviour 36:1533-1540.

Luh, H.-K., J. L. Gittleman, and M. Kot. 1995. Phylogenetic autocorrelation: a manual. Department of Zoology, University of Tennessee, Knoxville.

$\rightarrow$ Macedonia, J. M., and C. S. Evans. 1993. Variation among mammalian alarm call systems and the problem of meaning in animal signals. Ethology 93:177-197.

Macedonia, J. M., and K. F. Stanger. 1994. Phylogeny of the Lemuridae revisited: evidence from communication signals. Folia Primatologica 63:1-43.

Marler, P. 1977. The evolution of communication. Pages 45-70 in T. A. Sebeok, ed. How animals communicate. Indiana University Press, Bloomington.

1985. Representational vocal signals of primates. Pages 211-211 in B. Hölldobler and M. Lindauer, eds. Experimental behavioral ecology and sociobiology. Fischer, New York.

Marler, P., and J. Mitani. 1988. Vocal communication in primates and birds: parallels and contrasts. Pages 3-14 in D. Todt, P. Goedeking, and D. Symmes, eds. Primate vocal communication. Springer, Berlin.

Marler, P., C. S. Evans, and M. D. Hauser. 1992. Animal signals: motivational, referential, or both? Pages 66-86 in H. Papousek, U. Jürgens, and M. Papousek, eds. Nonverbal vocal communi- 
cation: comparative and developmental approaches. Cambridge University Press, Cambridge.

Martins, E. P. 1995. Phylogenies and comparative data: a microevolutionary perspective. Philosophical Transactions of the Royal Society of London B, Biological Sciences 349:85-91.

. 1996. Phylogenies, spatial autoregression, and the comparative method: a computer simulation test. Evolution 50:1750-1765.

Matocha, K. G. 1977. The vocal repertoire of Spermophilus tridecemlineatus. American Midland Naturalist 98:482-487.

McCarley, H. 1966. Annual cycle, population dynamics and adaptive behavior of Citellus tridecemlineatus. Journal of Mammalogy 47:294-316.

McShea, D. W. 1991. Complexity and evolution: what everybody knows. Biological Philosophy 6: 303-324.

1996. Metazoan complexity and evolution: is there a trend? Evolution 50:477-492.

Meier, P. T. 1985. Behavioral ecology, social organization and mating system of woodchucks (Marmota monax) in southeast Ohio. Ph.D. diss. Ohio University, Athens.

Michener, G. R. 1979. The circannual cycle of Richardson's ground squirrels in southern Alberta. Journal of Mammalogy 60:760-768.

1983. Kin identification, matriarchies, and the evolution of sociality in ground-dwelling sciurids. Pages 528-572 in J. F. Eisenberg and D. G. Kleiman, eds. Advances in the study of mammalian behavior. American Society of Mammalogists, [Stillwater, Okla.].

$\rightarrow$ Morton, E. S. 1975. Ecological sources of selection on avian sounds. American Naturalist 109:17-34.

Morton, M. L., and J. S. Gallup. 1975. Reproductive cycle of the Belding ground squirrel (Spermophilus beldingi beldingi): seasonal and age differences. Great Basin Naturalist 35: 427-433.

Mosolov, V. I., and V. A. Tokarsky. 1994. The black-capped marmot (Marmota camtschatica Pall.) in the Kronotsky Reserve. Pages 98-110 in V. Y. Rumiantsev, ed. Actual problems of marmots investigation. ABF, Moscow.

Murie, J. O., and G. R. Michener, eds. 1984. The biology of ground-dwelling squirrels. University of Nebraska Press, Lincoln.

Nikolskii, A. A. 1976. Alarm call of marmots as a specific character. Zoologicheskii Zhurnal 55:12141224.

Nottebohm, F. 1975. Vocal behavior in birds. Pages 287-332 in D. S. Farner, J. R. King, and K. C. Parkes, eds. Avian biology. Vol. 5. Academic Press, New York.

Nowak, R. M., and J. L. Paradiso. 1983. Walker's mammals of the world. 4th ed. Johns Hopkins University Press, Baltimore, Md.

Oaks, E. C., P. J. Young, G. L. Kirkland, Jr., and D. F. Schmidt. 1987. Spermophilus variegatus. Mammalian Species 272:1-8.

Ognev, S. I. 1963. Mammals of the U.S.S.R. and adjacent countries: rodents. Israel Program for Scientific Translations, Jerusalem.

$\rightarrow$ Ortega, J. C. 1990. Reproductive biology of the rock squirrel (Spermophilus variegatus) in southeastern Arizona. Journal of Mammalogy 71:448-457.

$\rightarrow-$. 1991. The annual cycles of activity and weight of rock squirrels (Spermophilus variegatus) in southeastern Arizona. American Midland Naturalist 126:159-171.

Owings, D. H., and D. F. Hennessy. 1984. The importance of variation in sciurid visual and vocal communication. Pages 169-200 in J. O. Murie and G. R. Michener, eds. The biology of ground-dwelling squirrels. University of Nebraska Press, Lincoln.

$\rightarrow$ Owings, D. H., and D. W. Leger. 1980. Chatter vocalizations of California ground squirrels: predatorand social-role specificity. Zeitschrift für Tierpsychologie 54:163-184.

Owings, D. H., M. Borchert, and R. Virginia. 1977. The behaviour of California ground squirrels. Animal Behaviour 25:221-230.

$\rightarrow$ Perrin, C., J. Coulon, and M. Le Berre. 1993a. Social behavior of alpine marmots (Marmota marmota): seasonal, group, and individual variability. Canadian Journal of Zoology 71:1945-1953.

$\rightarrow$ Perrin, C., D. Allaine, and M. Le Berre. 1993b. Socio-spatial organization and activity distribution of the alpine marmot Marmota marmota: preliminary results. Ethology 93:21-30. 
Pfeiffer, S. R. 1982. Variability in reproductive output and success of Spermophilus elegans ground squirrels. Journal of Mammalogy 63:284-289.

Philips, M., and S. N. Austad. 1990. Animal communication and social evolution. Pages 254-268 in M. Bekoff and D. Jamieson, eds. Interpretation and explanation in the study of animal behavior. Vol. 1. Interpretation, intentionality and communication. Westview, Boulder, Colo.

$\rightarrow$ Phillips, J. A. 1981. Growth and its relationship to the initial annual cycle of the golden-mantled ground squirrel, Spermophilus lateralis. Canadian Journal of Zoology 59:865-871.

$\rightarrow$ Pizzimenti, J. J., and G. D. Collier. 1975. Cynomys parvidens. Mammalian Species 52:1-5.

$\rightarrow$ Prum, R. O. 1994. Phylogenetic analysis of the evolution of alternative social behavior in the manakins (Aves: Pipridae). Evolution 48:1657-1675.

Purvis, A., and A. Rambaut. 1995. Comparative analysis by independent contrasts (CAIC): an Apple Macintosh application for analysing comparative data. Computer Applications in the Biosciences 11:247-251.

$\rightarrow$ Rasa, O. A. E. 1983. Dwarf mongoose and hornbill mutualism in the Taru Desert, Kenya. Behavioral Ecology and Sociobiology 12:181-190.

$\rightarrow$ Rausch, R. L., and V. R. Rausch. 1971. The somatic chromosomes of some North American marmots (Sciuridae), with remarks on the relationships of Marmota broweri Hall and Gilmore. Mammalia 35:85-101.

$\rightarrow$ Rayor, L. S. 1985. Effects of habitat quality on growth, age of first reproduction, and dispersal in Gunnison's prairie dogs (Cynomys gunnisoni). Canadian Journal of Zoology 63:28352840.

$\rightarrow$. 1988. Social organization and space-use in Gunnison's prairie dog. Behavioral Ecology and Sociobiology 22:69-78.

Reynolds, H. G., and F. Turkowski. 1972. Reproductive variations in the round-tailed ground squirrel as related to winter rainfall. Journal of Mammalogy 53:893-898.

$\rightarrow$ Rickart, E. A. 1986. Postnatal growth of the Piute ground squirrel (Spermophilus mollis). Journal of Mammalogy 67:412-416.

- 1987. Spermophilus townsendii. Mammalian Species 268:1-6.

$\rightarrow$ Robinson, S. R. 1981. Alarm communication in Belding's ground squirrels. Zeitschrift für Tierpsychologie 56:150-168.

$\rightarrow$ Rongstad, O. J. 1965. A life history study of thirteen-lined ground squirrels in southern Wisconsin. Journal of Mammalogy 46:76-87.

Ryan, M. J. 1988. Constraints and patterns in the evolution of anuran acoustic communication. Pages 637-677 in B. Fritzsch, M. J. Ryan, W. Wilczynski, T. E. Hetherington, and W. Walkowiak, eds. The evolution of the amphibian auditory system. Wiley, New York.

Sanders, P. T., and M. W. Ho. 1981. On the increase in complexity in evolution. II. The relativity of complexity and the principle of minimum increase. Journal of Theoretical Biology 90: 515-530.

Schleidt, W. M. 1973. Tonic communication: continual effects of discrete signs in animal communication systems. Journal of Theoretical Biology 42:359-386.

Schwagmeyer, P. L. 1980. Alarm calling behavior of the thirteen-lined ground squirrel, Spermophilus tridecemlineatus. Behavioral Ecology and Sociobiology 7:195-200.

Schwagmeyer, P. L., and C. H. Brown. 1981. Conspecific reaction to playback of thirteen-lined ground squirrel vocalizations. Zeitschrift für Tierpsychologie 56:25-32.

1983. Factors affecting male-male competition in thirteen-lined ground squirrels. Behavioral Ecology and Sociobiology 13:1-6.

Seyfarth, R., and D. Cheney. 1990. The assessment by vervet monkeys of their own and another species' alarm calls. Animal Behaviour 40:754-764.

Seyfarth, R., D. Cheney, and P. Marler. 1980. Vervet monkey alarm calls: semantic communication in a free-ranging primate. Animal Behaviour 28:1070-1094.

Shannon, C. E., and W. Weaver. 1949. The mathematical theory of communication. University of Illinois Press, Urbana.

Sherman, P. W. 1977. Nepotism and the evolution of alarm calls. Science (Washington, D.C.) 197: $1246-1253$. 
Shields, W. M. 1980. Ground squirrel alarm calls: nepotism or parental care? American Naturalist 116: 599-603.

Shriner, W. M., and P. B. Stacey. 1991. Spatial relationships and dispersal patterns in the rock squirrel, Spermophilus variegatus. Journal of Mammalogy 72:601-606.

Slade, N. A., and D. F. Balph. 1974. Population ecology of Uinta ground squirrels. Ecology 55: 989-1003.

Slobodchikoff, C. N., J. Kiriazis, C. Fischer, and E. Creef. 1991. Semantic information distinguishing individual predators in the alarm calls of Gunnison's prairie dogs. Animal Behaviour 42: $713-719$.

Smith, G. W., and D. R. Johnson. 1985. Demography of a Townsend ground squirrel population in southwestern Idaho. Ecology 66:171-178.

Snowdon, C. T. 1982. Linguistic and psycholinguistic approaches to primate communication. Pages 212-238 in C. T. Snowdon, C. H. Brown, and M. R. Petersen, eds. Primate communication. Cambridge University Press, Cambridge.

Snowdon, C. T., and M. Elowson. 1992. Ontogeny of primate vocal communication. Pages 279-290 in T. Nishida, W. C. McGrew, P. Marler, M. Pickford, and F. B. M. de Waal, eds. Topics in primatology. Vol. 1. Human origins. University of Tokyo Press, Toyko.

Streubel, D. P., and J. P. Fitzgerald. 1978. Spermophilus tridecemlineatus. Mammalian Species 103: $1-5$.

$\rightarrow$ Szathmáry, E., and J. Maynard Smith. 1995. The major evolutionary transitions. Nature (London) 374: $227-232$.

$\rightarrow$ Thomas, W. K., and S. L. Martin. 1993. A recent origin of marmots. Molecular Phylogenetics and Evolution 2:330-336.

$\rightarrow$ Turner, L. W. 1973. Vocal and escape responses of Spermophilus beldingi to predators. Journal of Mammalogy 54:990-993.

Waring, G. H. 1966. Sounds and communications of the yellow-bellied marmot (Marmota flaviventris). Animal Behaviour 14:177-183.

$\rightarrow$. 1970. Sound communications of black-tailed, white-tailed, and Gunnison's prairie dogs. American Midland Naturalist 83:167-185.

Waser, P. M. 1982. The evolution of male loud calls among mangabeys and baboons. Pages 117-143 in C. T. Snowdon, C. H. Brown, and M. R. Petersen, eds. Primate communication. Cambridge University Press, Cambridge.

Wiley, R. H., and D. G. Richards. 1978. Physical constraints on acoustic communication in the atmosphere: implications for the evolution of animal vocalizations. Behavioral Ecology and Sociobiology 3:69-94.

Winston, M. L., and C. D. Michener. 1977. Dual origin of highly social behavior among bees. Proceedings of the National Academy of Sciences of the USA 74:1135-1137.

Wistrand, H. 1974. Individual, social, and seasonal behavior of the thirteen-lined ground squirrel (Spermophilus tridecimlineatus). Journal of Mammalogy 55:329-347.

Wittenberger, J. F. 1979. The evolution of mating systems in birds and mammals. Pages 271-349 in P. Marler and J. G. Vandenbergh, eds. Handbook of behavioral neurobiology. Vol. 3. Social behavior and communication. Plenum, New York.

. 1981. Animal social behavior. Duxbury, Boston.

Wrangham, R. W. 1986. Evolution of social structure. Pages 282-296 in B. B. Smuts, D. L. Cheney, R. M. Seyfarth, and R. W. Wrangham, eds. Primate societies. University of Chicago Press, Chicago.

Wright-Smith, M. A. 1978. The ecology and social organization of Cynomys parvidens (Utah prairie $\operatorname{dog}$ ) in south central Utah. M.S. thesis. Indiana University, Bloomington.

$\rightarrow$ Zammuto, R. M., and J. S. Millar. 1985. Environmental predictability, variability, and Spermophilus columbianus life history over an elevational gradient. Ecology 66:1784-1794.

$\rightarrow$ Zegers, D. A. 1984. Spermophilus elegans. Mammalian Species 214:1-47. 